\title{
White Esophageal Mucosa and Black Gastric Mucosa: Upper Gastrointestinal Injury Due to Hydrochloric Acid Ingestion
}

\author{
Woong Cheul Lee, Tae Hee Lee and Jun-Hyung Cho \\ Institute for Digestive Research, Digestive Disease Center, Soonchunhyang University Hospital, Soonchunhyang University College of Medicine, \\ Seoul, Korea
}

Caustic ingestion can cause severe injury to the esophagus and stomach. The severity and extent of esophageal and gastric damage resulting from caustic ingestion depend upon several factors. In the present report, we describe the case of a 55-year-old schizophrenic man who drank $400 \mathrm{~mL}$ of hydrochloric acid. Endoscopy indicated the presence of white esophageal mucosa and black gastric mucosa, which is evident in the images taken before and after ingestion (Fig. 1).

Acid ingestion typically produces a superficial coagulation necrosis that results in thrombosis of underlying mucosal blood vessels and consolidation of connective tissue, thereby forming a protective eschar. ${ }^{1}$ Because acid solutions cause pain upon contact with the oropharynx, the amount of acid ingested tends to be limited. However, in the present case, the patient had schizophrenia, and despite experiencing pain, he drank $400 \mathrm{~mL}$ of hydrochloric acid. We believe that the excess hydrochloric acid injured the esophageal mucosa and subsequently turned the esophagus white, due to the development of mucosal edema, exudates, and superficial coagulation necrosis. Typically, when acid is ingested, it flows along the lesser curvature of the stomach towards the pylorus, and pylorospasm impairs emptying into the duodenum, producing stagnation and injury that is particularly prominent in the antrum. ${ }^{2}$ However, in the present case, excess acid stagnated in the stomach, and as a result, we believe that the gastric mucosa was damaged up to the transmural layer, causing the black coloring of the mucosa.

Received: December 31, 2012 Revised: April 28, 2013

Accepted: September 13, 2013

Correspondence: Tae Hee Lee

Institute for Digestive Research, Digestive Disease Center, Soonchunhyang University Hospital, Soonchunhyang University College of Medicine, 59 Daesagwan-ro, Yongsan-gu, Seoul 140-743, Korea

Tel: +82-2-709-9691, Fax: +82-2-709-9696, E-mail: iman0825@schmc.ac.kr

(a) This is an Open Access article distributed under the terms of the Creative Commons Attribution Non-Commercial License (http://creativecommons.org/ licenses/by-nc/3.0) which permits unrestricted non-commercial use, distribution, and reproduction in any medium, provided the original work is properly cited.
The severity and extent of esophageal and gastric damage resulting from caustic ingestion depend upon three major factors: corrosive properties of the ingested substance; duration of contact with the mucosa; and the amount, concentration, and physical form (solid or liquid) of the agent. ${ }^{3,4}$ Most ingestions occur in children, whereas the other cases involve psychotic, suicidal, or alcoholic subjects. ${ }^{5}$ The present case was a subject who was both psychotic and suicidal.

Caustic ingestion is usually accidental in children under the age of 5 years and intentional in adults and adolescents. Highly concentrated acids (hydrochloric, sulfuric, and phosphoric acid) present in toilet bowl or swimming pool cleaners, antirust compounds, or in battery fluid are less frequently ingested than alkalis. ${ }^{4}$ When acid remains on the esophagus, burns can occur within 4 hours and perforation can occur within 6 hours; in such cases, urgent endoscopy is indicated. In the present case, we performed esophagogastroduodenoscopy (EGD) within 4 hours of ingestion.

Alkali ingestions typically damage the esophagus to a greater extent than the stomach or duodenum, whereas acids cause more severe gastric injury. A study comparing outcomes of acid or alkali ingestion found that the outcomes were worse overall for those who ingested acid. ${ }^{6}$ Such patients had significantly more severe mucosal injury, were more likely to be hospitalized in the intensive care unit, were more likely to have systemic complications or perforation, and had higher mortality.

Caustic injuries to the gastrointestinal tract are classified pathologically, similarly to burns of the skin. First degree injury results from superficial mucosal damage and is characterized by the presence of focal or diffuse erythema, edema, and hemorrhage. The mucosal lining subsequently sloughs without scar formation. Second-degree injury is characterized by the presence of mucosal and submucosal damage, ulcerations, exudates, and vesicle formation. Eventually, granu- 


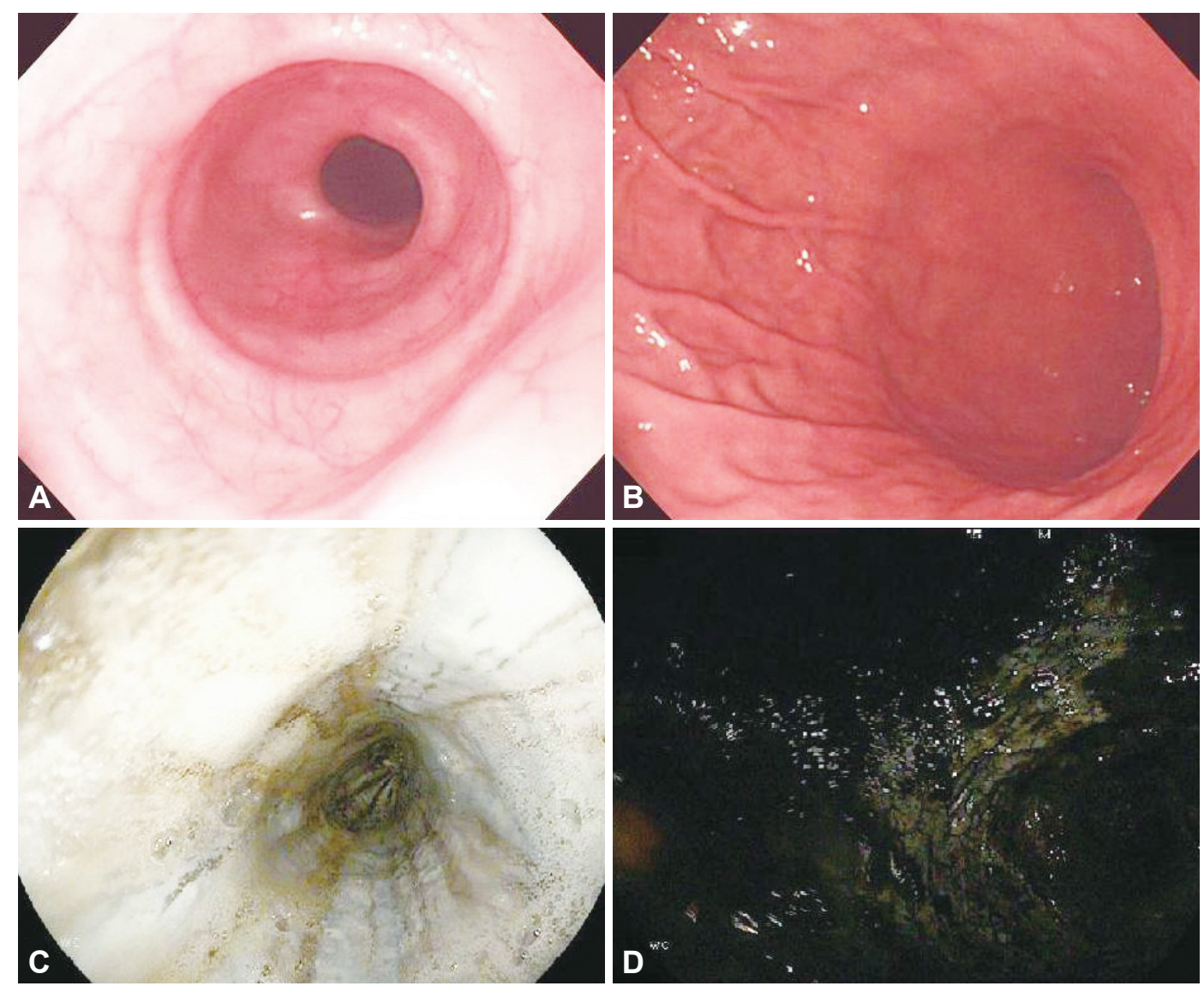

Fig. 1. Endoscopic findings. (A) Initial esophagoscopy. No abnormality is noted during the initial examination of the esophageal mucosa. (B) Initial gastroscopy. No abnormality is seen during the initial examination of the gastric mucosa, except for linear erythema. (C) Esophagoscopy after acid ingestion. Esophageal mucosa appears white and edematous. (D) Gastroscopy after acid ingestion: gastric mucosa appears black and necrotic.

lation tissue develops, followed by a fibroblastic reaction that produces a scar and possible stricture. Third degree injury is transmural and is characterized by the presence of deep ulcers along with black discoloration and perforation of the wall. Endoscopy should be performed as soon as possible-ideally within 24 hours -in order to assess the magnitude and extent of injury, according to the grading system. Subsequent management is determined based on the results of endoscopy.

Patients suspected of having serious ingestions (based on history, symptoms, or endoscopic findings) should generally be treated in a surgical or medical intensive care unit for the management of acute, life-threatening complications of injury (mediastinitis, peritonitis, respiratory distress, shock, and metabolic disorder) and to decrease the risk of developing late esophageal strictures. Each patient should be evaluated individually since the clinical picture varies widely, and signs and symptoms alone are an unreliable guide to injury. ${ }^{7}$ In the case of severe caustic damage, endoscopy should be performed within 24 hours. However, endoscopy is not needed for all patients and may be deferred at the physician's discretion. We experienced an interesting case of acid ingestion wherein en- doscopy indicated the presence of a white esophagus and black gastric mucosa; we provide a description of this case with images, along with a review of the literature.

\section{Conflicts of Interest}

The authors have no financial conflicts of interest.

\section{REFERENCES}

1. Fisher RA, Eckhauser ML, Radivoyevitch M. Acid ingestion in an experimental model. Surg Gynecol Obstet 1985;161:91-99.

2. Zargar SA, Kochhar R, Nagi B, Mehta S, Mehta SK. Ingestion of strong corrosive alkalis: spectrum of injury to upper gastrointestinal tract and natural history. Am J Gastroenterol 1992;87:337-341.

3. Goldman LP, Weigert JM. Corrosive substance ingestion: a review. Am J Gastroenterol 1984;79:85-90.

4. Wasserman RL, Ginsburg CM. Caustic substance injuries. J Pediatr 1985;107:169-174.

5. Kikendall JW. Caustic ingestion injuries. Gastroenterol Clin North Am 1991;20:847-857.

6. Poley JW, Steyerberg EW, Kuipers EJ, et al. Ingestion of acid and alkaline agents: outcome and prognostic value of early upper endoscopy. Gastrointest Endosc 2004;60:372-377.

7. Keh SM, Onyekwelu N, McManus K, McGuigan J. Corrosive injury to upper gastrointestinal tract: still a major surgical dilemma. World J Gastroenterol 2006;12:5223-5228. 